\title{
Long-acting nifedipine for hypertensive patients in the Middle East and Morocco: observations on efficacy and tolerability of monotherapy or combination therapy
}

\author{
This article was published in the following Dove Press journal: \\ Integrated Blood Pressure Control \\ 4 June 2013 \\ Number of times this article has been viewed
}

\author{
Raafat AL Ghoneim' \\ Abdalla Kamal Omar ${ }^{2}$ \\ VJ Sebastian ${ }^{3}$ \\ Roland Kassab ${ }^{4}$ \\ George Akijian ${ }^{5}$ \\ Meryem Hafiz ${ }^{6}$ \\ Birgit Schmidt ${ }^{7}$ \\ 'Department of Nephrology, Dr \\ Bakhsh Hospital, Jeddah, Saudi \\ Arabia; ${ }^{2}$ Open Specialist Clinics, \\ Dallah Hospital, Riyadh, Saudi \\ Arabia; ${ }^{3}$ Department of Cardiology, \\ International Modern Hospital, Dubai, \\ United Arab Emirates; ${ }^{4}$ Department \\ of Cardiology, St Joseph University \\ School of Medicine, Beirut, Lebanon; \\ ${ }^{5}$ Internal Medicine (private clinic), \\ Marka, Amman, Jordan; ${ }^{6}$ Medical \\ Department, Bayer SA, Casablanca, \\ Morocco; ${ }^{7}$ Global NIS, Bayer Vital \\ $\mathrm{GmbH}$, Leverkusen, Germany
}

\begin{abstract}
Background: The Middle Eastern and North African region of developing countries is associated with poor rates of blood pressure (BP) control and antihypertensive prescribing patterns. This post hoc analysis of data from an international observational study aimed to investigate the efficacy and tolerability of long-acting nifedipine $(30 \mathrm{mg}$ or $60 \mathrm{mg}$; monotherapy or in combination) in the Middle Eastern and Moroccan populations defined as having high cardiovascular risk.
\end{abstract}

Methods: This was a prospective, noninterventional, multicenter observational study. Observations from patients (aged $\geq 18$ years) with treated or untreated hypertension from the Middle East (Jordan, Saudi Arabia, Kuwait, Lebanon, Qatar, United Arab Emirates, and Yemen) and Morocco are presented. Hypertension grade and cardiovascular risk were defined at baseline, and systolic/diastolic BP change was defined at post-baseline visits ( $\leq 3)$. Adverse events and ratings of therapy efficacy and patient/physician satisfaction were recorded.

Results: The study included 1466 patients from the Middle East and 524 from Morocco. Characteristics of the populations differed, with a more severe hypertension profile in Moroccan patients. Despite these differences, nifedipine reduced BP to a similar extent in each group, with efficacy dependent on cardiovascular risk factors such as hypertension grade and age. Few adverse drug reactions occurred and nifedipine was well-tolerated in both populations. Efficacy and satisfaction with therapy were rated highly.

Conclusion: Good rates of BP control were observed with nifedipine in patients with moderateto-severe hypertension and high added risk. Published data in these countries suggest poor antihypertensive prescribing patterns and BP control; these data confirm this trend and suggest that suboptimal dosing may be prevalent.

Keywords: antihypertensive, safety, tolerability, hypertension, cardiovascular risk, blood pressure

\section{Introduction}

Middle Eastern countries have been associated with poor rates of blood pressure (BP) control and poor antihypertensive prescribing patterns. ${ }^{1-3}$ The cardiovascular $(\mathrm{CV})$ health of people living in developing countries and adopting a Western lifestyle is at risk due to rapidly increasing levels of obesity and metabolic syndrome. ${ }^{4,5}$ The Middle East and North Africa (MEN) is a World Bank-defined low- and middle-income region that faces an increasing $\mathrm{CV}$ health burden. ${ }^{6}$ Health expenditure in this region is also relatively low ( $\$ 103$ per capita on average), with Yemen spending as little as $\$ 38$ per capita. ${ }^{6}$
Correspondence: Raafat AL Ghoneim Dr Bakhsh Hospital, Anas Bin Malik Street, PO Box 6940, Jeddah 21452, Saudi Arabia

Tel +9660096626479666 Fax $+96600966265 I 7975$

Email labeebraafat@gmail.com 
BP control is a key factor for reducing CV mortality and morbidity, as shown in a number of randomized controlled trials. ${ }^{7,8}$ Despite these proven benefits, in clinical practice BP control often remains suboptimal, and nonadherence to hypertension medicines may play a large role in this. ${ }^{9}$ Observational studies can be an effective way of determining prescribing patterns and efficacy in real-life clinical settings. A recent international observational study showed that long-acting nifedipine (Adalat ${ }^{\circledR}$ OROS or nifedipine gastrointestinal therapeutic system [GITS]) provided effective BP reduction and was well-tolerated in a broad spectrum of patients seen in clinical practice. ${ }^{10}$ The efficacy of nifedipine treatment was also shown to be linked to hypertension grade, age, CV risk factors, and prior treatment.

The aim of this post hoc analysis was to examine the antihypertensive efficacy and tolerability of long-acting nifedipine OROS in the cohort of patients from the Middle East and Morocco; these patients were chosen to investigate $\mathrm{BP}$ control in the MEN region countries, which are associated with high $\mathrm{CV}$ risk and poor prescribing patterns.

\section{Materials and methods}

This study formed part of an international, prospective, multicenter observational study (study identifier: AL0301). ${ }^{10}$ Here we present results from patients included in the Middle East subgroup (Jordan, Saudi Arabia, Kuwait, Lebanon, Qatar, United Arab Emirates, and Yemen; study identifier: AL0301EG) studied between September 2005 and June 2006, and the Morocco subgroup (study identifier: AL0301MA) studied from November 2004 to June 2006.

The observation period for each subject included an initial visit at the start of nifedipine therapy and up to three follow-up visits. Prescription of nifedipine was decided by the treating physician, and dosing could be changed at any point during the study (30 mg and $60 \mathrm{mg}$ formulations were available).

\section{Inclusion criteria}

Men and women, aged $\geq 18$ years, with untreated or previously treated hypertension were recruited after nifedipine treatment had been proposed as part of their routine clinical care, and if they were considered as suitable by their physician. No additional investigations were performed and no patients were allocated systematically to treatment. According to the inclusion criteria as defined in the study protocol, patients were excluded if they had a contraindication for nifedipine (as described in the approved prescribing information), ${ }^{11}$ including known hypersensitivity to nifedipine, pregnancy, breastfeeding, or CV shock. Concomitant antihypertensive medication was permitted during the study.

\section{Observation parameters}

Systolic and diastolic BP (SBP, DBP) and heart rate readings were recorded at baseline and follow up visits in accordance with the treating physician's routine practice, and the daily dose of nifedipine was noted. Adverse events which occurred during nifedipine treatment were documented, and their relationship to the study drug was assessed by the treating physician on Adverse Event Forms, as part of the Case Report Form. Adverse events were coded using the Medical Dictionary for Regulatory Activities (MeDRA v9.1).

\section{Evaluation of treatment}

Hypertension grade and CV risk factors were defined at the initial visit according to European Society of Cardiology/ European School of Haematology (2003) criteria. ${ }^{12,13}$ Reductions in SBP and DBP from first to last visit were calculated and stratified by hypertension grade and risk factors. The percentage of patients achieving their target BP was assessed. The physicians' rating of treatment efficacy and tolerability was documented on a four-point scale ("very good", "good", "sufficient", and "insufficient") at the last documented visit. Satisfaction with therapeutic efficacy and patient satisfaction with treatment were assessed by the treating physician using a three-point scale ("very satisfied", "satisfied", and "not satisfied"). The likelihood of continuation of nifedipine therapy was also recorded.

\section{Statistical methods}

The safety and intention-to-treat populations were identical in this study and included all patients who received at least one dose of nifedipine. Descriptive and explorative analyses were performed based on non-missing data in this population for efficacy, safety, and tolerability outcomes. Quantitative efficacy (BP reduction) evaluations were based on patients for whom data were available for at least one follow-up visit.

Descriptive and explorative statistical analyses were conducted with SAS ${ }^{\circledR}$ for Windows, release 9.1 (SAS Institute Inc, Cary, NC, USA).

\section{Results}

\section{Characterization of study population}

A total of 1486 patients were included in the Middle East and 524 patients in Morocco. There were no exclusions from the Moroccan cohort, while in the Middle East cohort 20 patients 
were excluded due to protocol violations $(n=12$ retrospective documentation, $n=7$ empty records without documentation, and $n=1$ double data entry). The baseline characteristics of each population are summarized in Table 1. The Middle Eastern population was approximately two-thirds male to one-third female, while in the Moroccan population this ratio was reversed. The Moroccan patients had a slightly higher mean age (60.9 years) than their Middle Eastern counterparts (51.3 years), which corresponded to twice the percentage of Moroccan patients with age as a risk factor (44.3\% versus $20.6 \%$ ). The Moroccan population also contained a higher proportion of patients with abdominal obesity as a risk factor (33.6\% compared with $26.9 \%$ for the Middle East), but lower percentages of patients with dyslipidemia, diabetes mellitus, or a family history of $\mathrm{CV}$ disease, and fewer smokers (Table 1). However, the Moroccan population showed a more severe hypertension profile at baseline and substantially higher added risk than the Middle Eastern population (Table 2). This higher added risk was largely a consequence of higher baseline SBP in this population, more patients with severe hypertension, and a tendency

Table I Population baseline characteristics

\begin{tabular}{|c|c|c|}
\hline Variable & $\begin{array}{l}\text { Middle East } \\
(n=1466)\end{array}$ & $\begin{array}{l}\text { Morocco } \\
(n=524)\end{array}$ \\
\hline Male, n (\%) & $909^{\mathrm{a}}(62.0)$ & $197(37.6)$ \\
\hline Female, n (\%) & $493^{\mathrm{a}}(33.6)$ & $327(62.4)$ \\
\hline Age, years, mean (SD) $(n=1318 / 522)$ & $51.3(11.4)$ & $60.9(10.8)$ \\
\hline $\begin{array}{l}\text { Body mass index, } \mathrm{kg} / \mathrm{m}^{2}, \text { mean }(\mathrm{SD}) \\
(\mathrm{n}=1316 / 522)\end{array}$ & $29.4(4.7)$ & $28.1(5.0)$ \\
\hline Risk factors, n (\%) & 1308 (89.2) & $452(86.3)$ \\
\hline $\begin{array}{l}\text { Age }(\text { men }>55 \text { years; } \\
\text { women }>65 \text { years) }\end{array}$ & $302(20.6)$ & $232(44.3)$ \\
\hline Family history of cardiovascular disease & $566(38.6)$ & $145(27.7)$ \\
\hline Dyslipidemia & $6 I 1(41.7)$ & $100(19.1)$ \\
\hline $\begin{array}{l}\text { Abdominal obesity (as determined } \\
\text { by the treating physician) }\end{array}$ & $394(26.9)$ & $176(33.6)$ \\
\hline Smoking & $364(24.8)$ & $46(8.8)$ \\
\hline Diabetes mellitus & $381(26.0)$ & $92(17.6)$ \\
\hline C-reactive protein $\geq 1 \mathrm{mg} / \mathrm{dL}$ & $35(2.4)$ & $4(0.8)$ \\
\hline Associated clinical conditions, ${ }^{\mathrm{b}} \mathrm{n}(\%)$ & $330(22.5)$ & $123(23.5)$ \\
\hline Concomitant diseases, ${ }^{\mathrm{c}} \mathrm{n}(\%)$ & $754(51.4)$ & $357(68.1)$ \\
\hline Target-organ damage, ${ }^{\mathrm{d}} \mathrm{n}(\%)$ & $482(32.9)$ & $155(29.6)$ \\
\hline Previously untreated for hypertension, n (\%) & $577(39.4)$ & $292(55.7)$ \\
\hline Previously treated for hypertension, n (\%) & $889(60.6)$ & $232(44.3)$ \\
\hline I antihypertensive & $624(42.6)$ & $202(38.5)$ \\
\hline 2 antihypertensives & $223(15.2)$ & $28(5.3)$ \\
\hline 3 antihypertensives & $39(2.7)$ & $2(0.4)$ \\
\hline 4 antihypertensives & $3(0.2)$ & - \\
\hline
\end{tabular}

Notes: ${ }^{a} 64$ missing patients for gender assessment; bheart disease, peripheral vascular disease, cerebrovascular disease, renal disease, advanced retinopathy; 'coded according to Medical Dictionary for Regulatory Activities (MedDRA) system organ class; ' ${ }^{2}$ therosclerosis, left ventricular hypertrophy, microalbuminuria, increased serum creatinine.

Abbreviation: SD, standard deviation.
Table 2 Stage of hypertension and overall risk stratification for each population at baseline ${ }^{a}$

\begin{tabular}{|c|c|c|}
\hline & $\begin{array}{l}\text { Middle East } \\
n(\%) \\
n=1466^{b}\end{array}$ & $\begin{array}{l}\text { Morocco } \\
\text { n (\%) } \\
\mathbf{n}=\mathbf{5 2 4}\end{array}$ \\
\hline \multicolumn{3}{|c|}{ Stage of hypertension [systolic/diastolic] } \\
\hline $\begin{array}{l}\text { Normal and high normal blood pressure } \\
{[120-139 / 80-89] \mathrm{mmHg}}\end{array}$ & $14(1.0)$ & $\mathrm{I}(0.2)$ \\
\hline $\begin{array}{l}\text { Grade I hypertension (mild) } \\
\text { [140-159/90-99] mmHg }\end{array}$ & $205(14.0)$ & $8(1.5)$ \\
\hline $\begin{array}{l}\text { Grade } 2 \text { hypertension (moderate) } \\
\text { [160-179/100-109] mmHg }\end{array}$ & $732(49.9)$ & $108(20.6)$ \\
\hline $\begin{array}{l}\text { Grade } 3 \text { hypertension (severe) } \\
{[\geq \mid 80 / \geq 110] \mathrm{mmHg}}\end{array}$ & $406(27.7)$ & $319(60.9)$ \\
\hline $\begin{array}{l}\text { Isolated systolic hypertension } \\
{[\geq 140 /<90] \mathrm{mmHg}}\end{array}$ & $106(7.2)$ & $88(16.8)$ \\
\hline Overall risk & & \\
\hline Average risk & $6(0.4)$ & - \\
\hline Low added risk & $37(2.5)$ & $2(0.4)$ \\
\hline Moderate added risk & $40 \mathrm{I}(27.4)$ & $89(17.0)$ \\
\hline High added risk & $176(12.0)$ & $56(10.7)$ \\
\hline Very high added risk & $843(57.5)$ & $377(71.9)$ \\
\hline
\end{tabular}

Notes: ${ }^{\text {AAccording }}$ to European Society of Cardiology/European School of Haematology guideline 2003 based on World Health Organization/International Society of Hypertension guidelines 1999;12,13 bthree patients had data missing.

towards a greater number of concomitant risks and diseases (patients with three or more concomitant diseases: Morocco 17.6\%, Middle East 9.5\%).

\section{Antihypertensive medication}

The course of the study for each population is shown in Figure 1, along with information on the dosing of nifedipine (30 mg versus $60 \mathrm{mg}$ ) and levels of concomitant antihypertensive medication at baseline.

Two-thirds (67.1\%) of the Middle Eastern population initially received $30 \mathrm{mg}$ of nifedipine, and $29.3 \%$ received $60 \mathrm{mg}$. This equalized at the final visit, with $46.4 \%$ and $45.2 \%$ receiving $30 \mathrm{mg}$ and $60 \mathrm{mg}$ of nifedipine, respectively. In the Moroccan population, however, the proportions of patients receiving $30 \mathrm{mg}$ and $60 \mathrm{mg}$ stayed similar throughout the study $(79.4 \%$ and $18.7 \%$ at initial visit; $76.6 \%$ and $21.1 \%$ at final visit, respectively). Approximately three-quarters $(76.3 \%)$ of the Middle Eastern population remained on their initial dose of nifedipine during the study, compared with the vast majority $(91.4 \%)$ of the Moroccan patients.

More than half (52.5\%) of Middle Eastern patients were taking concomitant antihypertensive medication at baseline, compared with one-third (32.1\%) of Moroccan patients. The classes of concomitant antihypertensive medication being taken by patients from each region are shown in Table 3. 

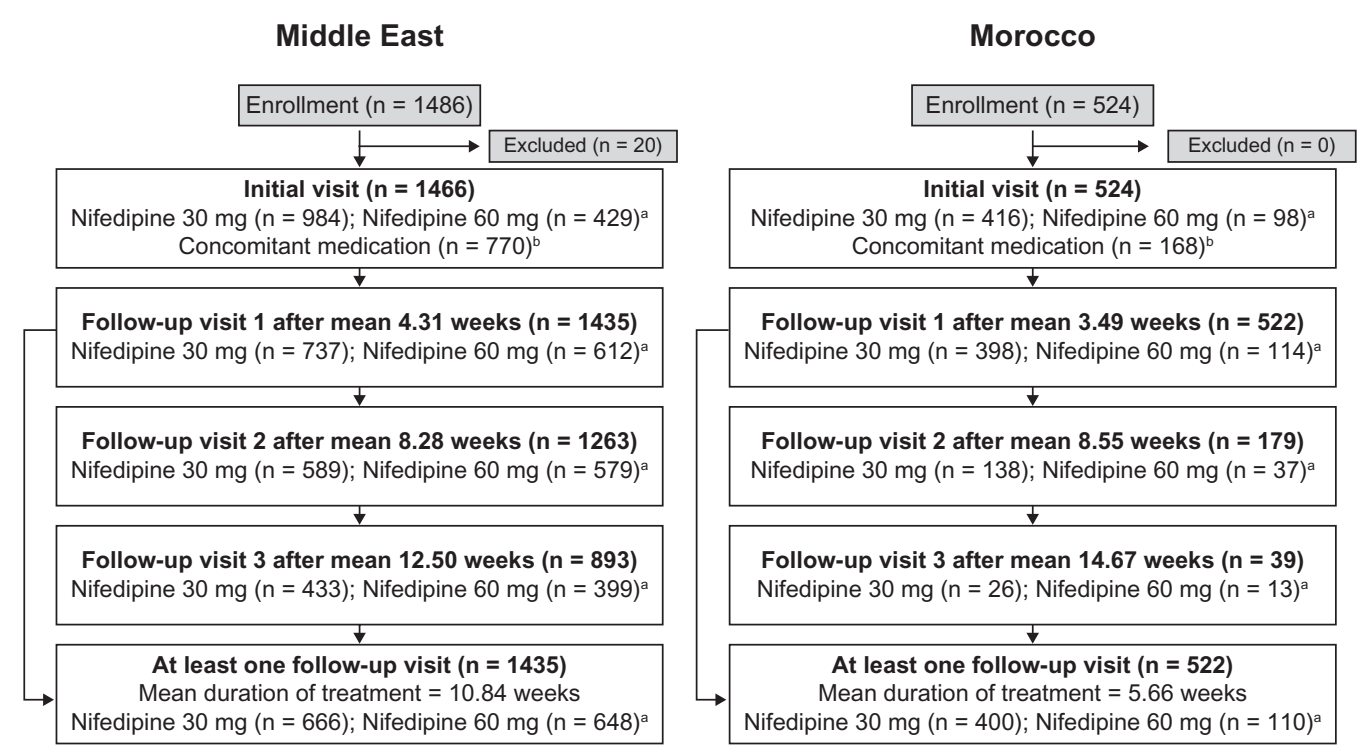

Figure I Study course for each population and antihypertensive dosing.

Notes: a'Some doses were missing or patients were using other doses; ${ }^{b}$ concomitant medication included angiotensin converting enzyme inhibitors, type I angiotensin IIreceptor antagonists, $\beta$-blocking agents, calcium channel blockers, diuretics, and other antihypertensives.

\section{Effect of nifedipine on hypertensive parameters}

Despite differences in the profiles of the two populations (including starting SBP), nifedipine reduced SBP and DBP to a similar extent in both the Middle Eastern and Moroccan patients (Figure 2). Mean SBP and DBP in each population decreased gradually over the course of the study (Figure 2). The mean reduction in SBP from initial to last visit was substantial in each population, decreasing by $31.3 \mathrm{mmHg}(19 \%$; from $164.4 \mathrm{mmHg}$ to $133.1 \mathrm{mmHg}$ ) in the Middle Eastern population, and by $38.6 \mathrm{mmHg}$ ( $21 \%$; from $184.0 \mathrm{mmHg}$ to $145.4 \mathrm{mmHg}$ ) in Moroccan patients (Table 4). Similarly, a reduction in DBP of $16.8 \mathrm{mmHg}$ (17\%; from $99.0 \mathrm{mmHg}$ to $82.2 \mathrm{mmHg}$ ) was seen in the Middle Eastern population, and of $14.9 \mathrm{mmHg}$ (15\%; from $98.0 \mathrm{mmHg}$ to $83.1 \mathrm{mmHg}$ ) in the Moroccan population.

Table 3 Classes of concomitant antihypertensive medication intake

\begin{tabular}{lll}
\hline Antihypertensive class & $\begin{array}{l}\text { Middle East } \mathbf{n}(\%) \\
\mathbf{n}=\mathbf{7 7 0}(\mathbf{5 2 . 5 )}\end{array}$ & $\begin{array}{l}\text { Morocco } \mathbf{n}(\%) \\
\mathbf{n}=168(32.1)\end{array}$ \\
\hline ACE inhibitors & $200(13.6)$ & $35(6.7)$ \\
Angiotensin-receptor & $220(15.0)$ & $2(0.4)$ \\
antagonists & & \\
Beta blocking agents & $204(13.9)$ & $37(7.1)$ \\
Calcium channel blockers & $25(1.7)$ & $8(1.5)$ \\
Diuretics & $342(23.3)$ & $112(21.4)$ \\
Other & $38(2.6)$ & $7(1.3)$ \\
\hline
\end{tabular}

Abbreviation: ACE, angiotensin converting enzyme.
Absolute changes in SBP and DBP varied according to initial hypertension grade, with reductions in BP increasing proportionally with baseline SBP or DBP (Figure 3). Absolute changes in SBP and DBP also varied according to CV risk factors (Table 4), with increasing age and presence of severe hypertension appearing to have the largest effect on mean BP reduction in both populations.

Over one-third (36.6\%) of all patients from the Middle East achieved their target BP with nifedipine therapy, whereas in Morocco only $14.7 \%$ reached their goals. The numbers and

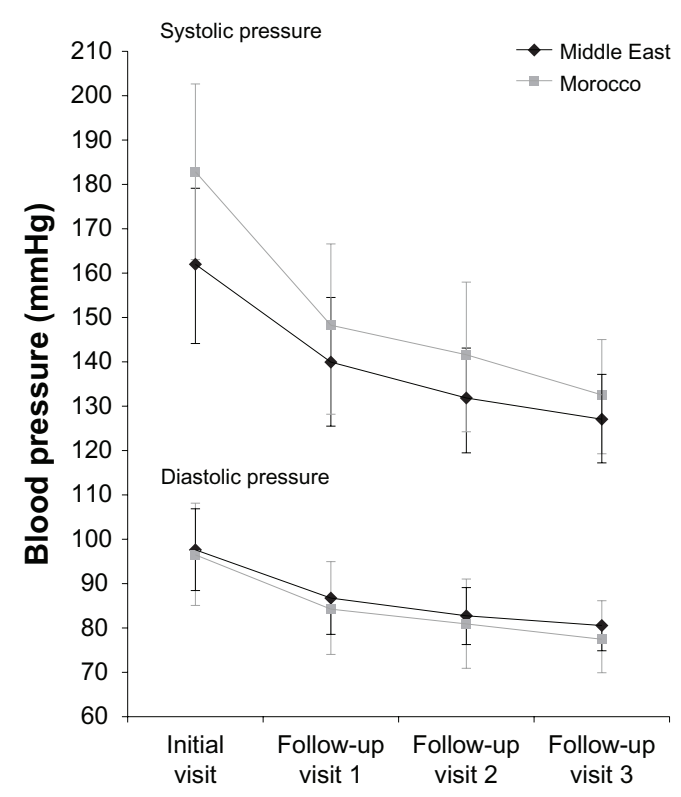

Figure $\mathbf{2}$ Mean systolic and diastolic blood pressure in each population by visit. Note: Error bars represent standard deviations. 
Table 4 Mean reduction in systolic blood pressure/diastolic blood pressure (SBP/DBP; $\mathrm{mmHg}$ ) achieved with nifedipine (initial to last visit), according to cardiovascular risk factors

\begin{tabular}{|c|c|c|c|c|}
\hline & \multicolumn{2}{|c|}{ Middle East } & \multicolumn{2}{|l|}{ Morocco } \\
\hline & $\begin{array}{l}\Delta \text { SBP } \\
(\mathrm{mmHg})\end{array}$ & $\begin{array}{l}\Delta \mathrm{DBP} \\
(\mathrm{mmHg})\end{array}$ & $\begin{array}{l}\Delta \text { SBP } \\
(\mathrm{mmHg})\end{array}$ & $\begin{array}{l}\triangle \mathrm{DBP} \\
(\mathrm{mmHg})\end{array}$ \\
\hline All patients & 31.2 & 16.8 & 38.6 & 14.9 \\
\hline Obesity & 31.7 & 17.1 & 37.8 & 15.2 \\
\hline Smoking & 30.6 & 17.5 & 35.2 & 13.5 \\
\hline \multicolumn{5}{|l|}{ Age } \\
\hline$<30$ years & 30.7 & 21.5 & 27.5 & 12.5 \\
\hline 30-39 years & 27.7 & 18.2 & 39.6 & 17.1 \\
\hline $40-49$ years & 29.3 & 17.8 & 36.1 & 13.6 \\
\hline $50-59$ years & 32.4 & 16.2 & 38.9 & 14.8 \\
\hline $60-69$ years & 34.2 & 15.4 & 39.1 & 15.4 \\
\hline 70-79 years & 34.7 & 14.8 & 38.5 & 14.6 \\
\hline$\geq 80$ years & 41.3 & 11.6 & 42.0 & 15.3 \\
\hline Diabetes & 31.3 & 17.0 & 36.0 & 12.8 \\
\hline \multicolumn{5}{|c|}{ Hypertension grade* } \\
\hline Grade Ia & 13.2 & 10.5 & - & 12.0 \\
\hline Grade Ib & 21.9 & 14.1 & 21.3 & 11.7 \\
\hline Grade 2a & 29.2 & 17.3 & 24.9 & 14.2 \\
\hline Grade $2 b$ & 35.7 & 21.7 & 30.7 & 22.0 \\
\hline Grade 3 & 50.6 & 27.9 & 44.9 & 25.1 \\
\hline \multicolumn{5}{|c|}{ Previously treated } \\
\hline$<$ I year & 32.2 & 17.2 & 36.1 & 13.5 \\
\hline I-5 years & 29.1 & 16.1 & 36.2 & 16.1 \\
\hline $6-10$ years & 32.5 & 16.2 & 37.7 & 13.2 \\
\hline$>10$ years & 29.8 & 12.8 & 41.7 & 16.7 \\
\hline
\end{tabular}

Notes: *Hypertension grades defined as SBP/DBP: Grade Ia, 140-149/90-94 mmHg Grade Ib, 150-159/95-99 mmHg; Grade 2a, 160-169/100-104 mmHg; Grade 2b, 170-179/105-109 mmHg; Grade 3, $\geq 180 / \geq 110 \mathrm{mmHg}$.

percentages of patients achieving their treatment goals varied with risk factor and hypertension grade in each population (Table 5). Within each population, comparable proportions of patients reached their goals in the low to high added risk categories $(70 \%-87 \%$ in the Middle East; $30 \%-50 \%$ in Morocco), but few very high added risk patients reached their goals $(8.3 \%$ and $4.5 \%$ in the Middle East and Morocco, respectively). Likewise, much better achievement of goals was seen for mild-to-moderate hypertension patients, but few severe hypertension patients reached their targets (Table 5).

While the absolute reductions in SBP and DBP in patients receiving nifedipine monotherapy and combination therapy were similar (Figure 4), the patients receiving combination therapy tended to have higher baseline readings, meaning that greater proportions of patients on nifedipine monotherapy reached their target BP than those taking combination therapies (Table 5 and Figure 4).

The treating physicians' overall assessments of efficacy were similar for each population (Table 6). The efficacy of nifedipine was rated as "very good" or "good" in the majority of patients (Middle East, 90.7\%; Morocco, $88.2 \%$ ). In either population, there were few differences between the efficacy ratings for men and women, and between patients aged $<65$ years versus those $\geq 65$ years In the Moroccan population (but not in the Middle East), efficacy was rated as "good" or "very good" slightly more frequently in pretreated patients than in those who had not been pretreated $(90.1 \%$ and $86.6 \%$, respectively). In both the Middle Eastern and Moroccan populations, the efficacy of nifedipine monotherapy was more often rated "good" or "very good" than for combination therapy (Middle East, 93.4\% versus 88.2\%; Morocco, 90.2\% versus $83.9 \%$ ). Patients with grade 3 hypertension were less often assessed as achieving "good" or "very good" for efficacy ratings compared with those with grade 2 hypertension (Middle East, $87.4 \%$ versus 92.8\%; Morocco, $85.0 \%$ versus $91.7 \%)$.

\section{Tolerability and safety}

Overall, nifedipine was well tolerated in both the Middle Eastern and Moroccan populations, with tolerability rated

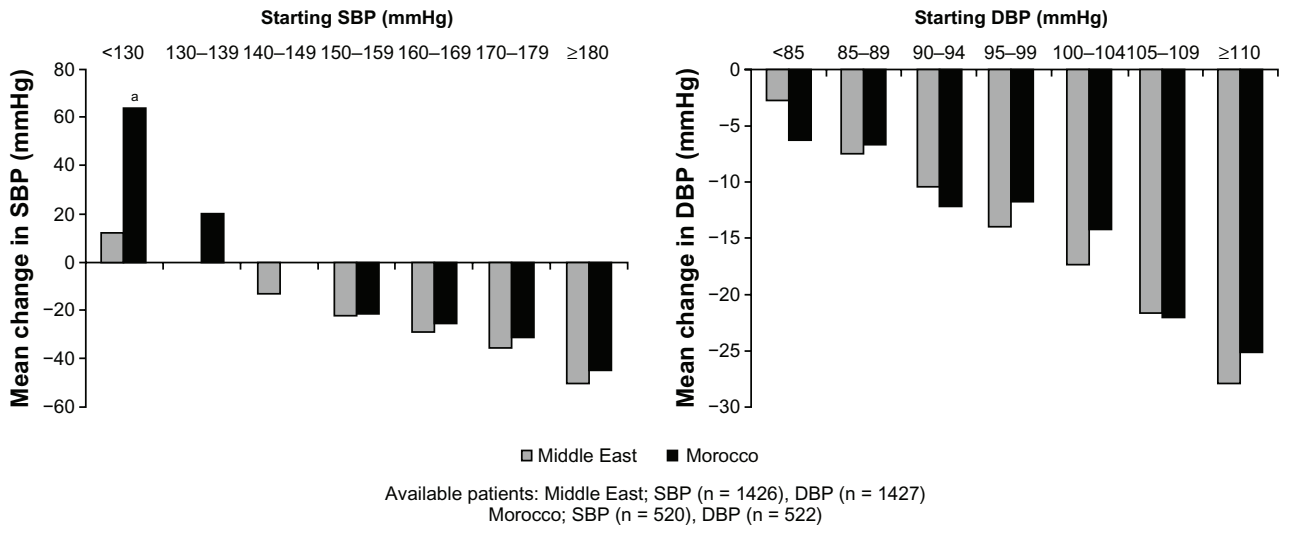

Figure 3 Mean change in SBP and DBP $(\Delta \mathrm{mmHg})$ achieved from initial to final visit for each population, according to initial SBP and DBP. Notes: ane patient with a low starting $\mathrm{BP}(<130 \mathrm{mmHg})$ showed an increase in SBP of $63 \mathrm{mmHg}$. The reason for this is unknown. Abbreviations: BP, blood pressure; DBP, diastolic BP; SBP, systolic BP. 
Table 5 Patients reaching target blood pressure in each population, by risk category and hypertension grade (determined at baseline), and by therapy

\begin{tabular}{lll}
\hline & $\begin{array}{l}\text { Middle East } \\
\mathbf{n}(\%)\end{array}$ & $\begin{array}{l}\text { Morocco } \\
\mathbf{n}(\%)\end{array}$ \\
\hline $\begin{array}{l}\text { Total patients } \\
\text { Risk category }\end{array}$ & $536(36.6)$ & $77(14.7)$ \\
Average risk & $6(100)$ & - \\
Low added risk & $32(86.5)$ & $1(50.0)$ \\
Moderate added risk & $304(75.8)$ & $42(47.2)$ \\
High added risk & $124(70.5)$ & $17(30.4)$ \\
Very high added risk & $70(8.3)$ & $17(4.5)$ \\
Hypertension grades & & \\
Normal and high normal BP & $11(78.6)$ & - \\
Grade I (mild) & $102(49.8)$ & $6(75.0)$ \\
Grade 2 (moderate) & $335(45.8)$ & $34(31.5)$ \\
Grade 3 (severe) & $38(9.4)$ & $16(5.0)$ \\
Isolated systolic hypertension & $50(47.2)$ & $21(23.9)$ \\
Therapy & & $71(19.9)$ \\
Nifedipine monotherapy & $305(43.8)$ & $6(3.6)$ \\
Combination therapy & $231(30.0)$ &
\end{tabular}

Abbreviation: BP, blood pressure.

by their physicians as "good" or "very good" in $88.1 \%$ and $90.6 \%$ patients, respectively.

Adverse events occurred in 81/1466 (5.53\%) of Middle Eastern patients and in 9/524 (1.72\%) of the Moroccan population (Table 7). Of these, 65 (4.43\%) and 7 (1.34\%) events, respectively, were designated as drug-related. The most common adverse drug reaction (ADR) was headache in both populations. Other ADRs reported included peripheral edema, flushing, and palpitations in the Middle Eastern group, and peripheral edema, dyspepsia, and chest pain in the Moroccan patients.

In the Moroccan population no serious adverse events occurred, and all events resolved within the course of the study. One serious ADR (severe headache) occurred in a Middle Eastern patient; nifedipine therapy was permanently discontinued, and the event resolved. Overall in the Middle Eastern population, 24 (1.64\%) adverse events improved, $60(4.09 \%)$ resolved, and $8(0.55 \%)$ remained unchanged at the end of the study.

\section{Satisfaction with nifedipine therapy}

Treating physicians reported high satisfaction for their patients in both populations: in the Middle East, 93.5\% of physicians were "satisfied" or "very satisfied" with nifedipine therapy, while in Morocco the percentage was 96.2\%. Physicians in the Middle East wanted to continue nifedipine therapy in $86.7 \%$ of their patients, while Moroccan physicians wanted to continue treatment in $94.7 \%$ of patients.
Middle East

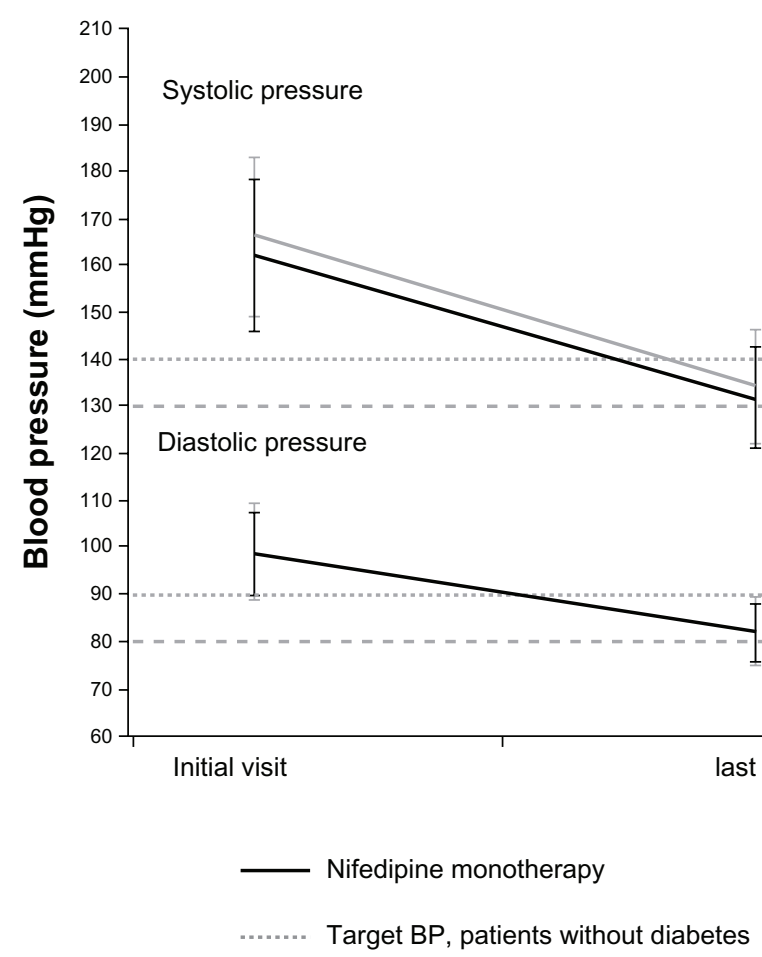

Morocco
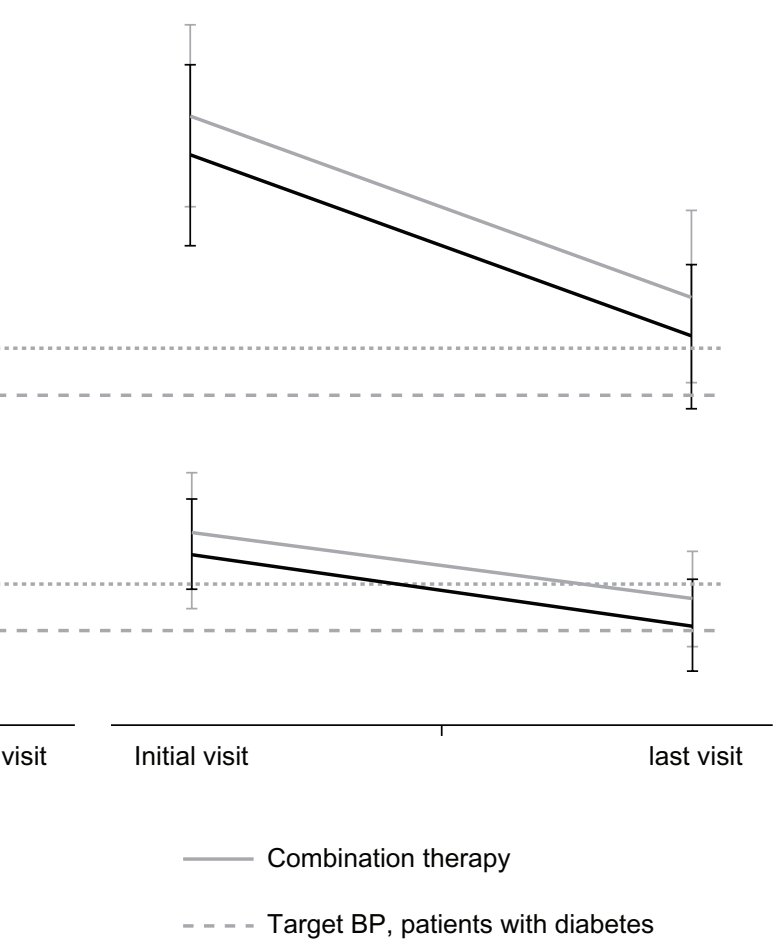

Figure 4 Mean systolic and diastolic blood pressure in each population at initial and last visit by type of therapy (nifedipine monotherapy or combined therapy). Note: Error bars represent standard deviations. 
Table 6 Overall physician's assessment of efficacy for each population

\begin{tabular}{lllll}
\hline Assessment (\%) & Very good & Good & Sufficient & Insufficient \\
\hline $\begin{array}{c}\text { Middle East } \\
\mathrm{n}=1466^{\mathrm{b}}\end{array}$ & 60.8 & 29.9 & 4.4 & 2.0 \\
$\begin{array}{l}\text { Morocco } \\
\mathrm{n}=524\end{array}$ & 57.6 & 30.5 & 8.0 & 3.8 \\
\hline
\end{tabular}

Notes: aValues rounded to I decimal place; ${ }^{\mathrm{b}} 2.9 \%$ of patients had data missing.

Patient satisfaction with nifedipine therapy was reported by treating physicians to be high; $89.2 \%$ in the Middle East and $95.0 \%$ in Morocco.

\section{Discussion}

The aim of this post-hoc analysis was to investigate the efficacy and safety of nifedipine therapy in the Middle Eastern and Moroccan populations included in a recent international observational study. Within these high CV risk populations, nifedipine therapy (monotherapy or in combination) lowered SBP and DBP to a similar extent, despite differences in the characteristics of the patients from each population. Mean reductions in SBP of $31.3 \mathrm{mmHg}$ and $38.6 \mathrm{mmHg}$, and in DBP of $16.8 \mathrm{mmHg}$ and $14.9 \mathrm{mmHg}$, were achieved in the Middle Eastern and Moroccan populations, respectively. Absolute reductions in $\mathrm{BP}$ were reliant on patient characteristics and CV risk factors. Nifedipine was associated with few adverse events, and both the efficacy and tolerability of nifedipine therapy were rated highly by treating physicians.

Patients from the Middle East and Morocco were chosen for this post-hoc analysis as they represent a region of countries with developing economies that are adopting a

Table 7 Incidence of AEs and ADRs occurring at a frequency of $>0.1 \%$ in each population during treatment with nifedipine

\begin{tabular}{|c|c|c|c|c|}
\hline \multirow[t]{2}{*}{ Event, $n^{a}(\%)$} & \multicolumn{2}{|c|}{ Middle East } & \multicolumn{2}{|c|}{ Morocco } \\
\hline & AEs & ADRs & AEs & ADRs \\
\hline Total & 81 (5.53) & $65(4.43)$ & $9(1.72)$ & $7(1.34)$ \\
\hline Headache & $28^{\mathrm{b}}(1.91)$ & $22(1.50)$ & $6(1.15)$ & $4(0.76)$ \\
\hline Peripheral edema & $26(1.77)$ & $23(1.57)$ & I (0.19) & I (0.19) \\
\hline Flushing & $15(1.02)$ & $12(0.82)$ & - & - \\
\hline Palpitations & II (0.75) & $9(0.6 \mathrm{I})$ & - & - \\
\hline Edema & $8(0.55)$ & $5(0.34)$ & - & - \\
\hline Dyspepsia & - & - & I (0.19) & I (0.19) \\
\hline Vomiting & - & - & I (0.19) & - \\
\hline Chest pain & - & - & I (0.19) & I (0.19) \\
\hline Abdominal pain & $2(0.14)$ & $2(0.14)$ & - & - \\
\hline Tachycardia & $2(0.14)$ & - & - & - \\
\hline
\end{tabular}

Notes: aMultiple responses, patient-based, MeDRA-coded; 'bserious event in one patient.

Abbreviations: ADR, adverse drug reaction; $A E$, adverse event; MeDRA, Medical Dictionary for Regulatory Activities.
Western lifestyle and its associated risks. ${ }^{6}$ Both sets of MEN populations were considered to have high $\mathrm{CV}$ risk; however, the Middle Eastern and Moroccan patients had different characteristics and risk profiles. The Moroccan patients were older (nearly double with advanced age as a risk factor), contained more females, and had slightly raised abdominal obesity, but lower frequency of other $\mathrm{CV}$ risk factors (history of $\mathrm{CV}$ disease, smoking, diabetes, or dyslipidemia) compared with their Middle Eastern counterparts. Despite this, the Moroccan population had a more severe hypertension profile and greater added risk versus the Middle Eastern patients. Over half of the Moroccan patients had not previously been treated for hypertension, which may partially explain the more severe profile of these patients. This lack of prior hypertension treatment may also indicate that the Moroccan healthcare system suffers from suboptimal screening and management of patients at risk of $\mathrm{CV}$ disease. ${ }^{14}$

Despite differences in the characteristics of the two populations, nifedipine resulted in similar BP reductions in the Middle Eastern and Moroccan patients. The magnitude of the response to antihypertensive treatment is directly related to the starting $\mathrm{BP},{ }^{15}$ and this relationship could be seen similarly in both the Middle East and Moroccan populations in this study (Figure 3 ). Around $80 \%$ of each population had grade 2 or 3 hypertension at baseline, and the absolute reduction in BP was similar for these subgroups of patients in each cohort (Table 4). BP is only one parameter of CV risk. Small differences in BP reductions may, in part, reflect differences in CV risk (such as age, diabetes, etc); however, these factors may have more of an influence on long-term $\mathrm{CV}$ outcomes than short-term BP reduction.

Randomized clinical trials have shown that the doseresponse relationship between BP and the risk of ischemic heart disease and stroke is proportional, across a range of BP values. ${ }^{7}$ For a $5 \mathrm{mmHg}$ reduction in DBP, the estimated risk reduction for stroke is $33 \%$, and for ischemic heart disease is $20 \%{ }^{7}$ Target BP values were reached in only $36.6 \%$ and $14.7 \%$ of patients from the Middle East or Morocco, respectively; however, the absolute reductions in BP attained with nifedipine are highly clinically relevant, and should substantially improve patient prognosis.

In this study, the Moroccan patients presented with much greater added risk compared with their Middle Eastern counterparts, and fewer of them reached their target BP. Evidence has underlined the benefits of antihypertensive therapy that attains currently recommended target BPs $(<140 / 90 \mathrm{mmHg}$ in the general population and $<130 / 80 \mathrm{mmHg}$ in high risk patients, such as those with diabetes or proteinuria). ${ }^{16}$ 
However, in clinical practice BP control is often suboptimal, with patients failing to reach recommended BP targets due to a number of limiting factors, including poor adherence to medication, insufficient patient-physician communication, deficient implementation of recommended guidelines, and suboptimal drug dosing. ${ }^{16}$ In the current noninterventional study, a low rate of $60 \mathrm{mg}$ nifedipine prescription was observed in both populations (initial and final visit rates of prescription: Middle East, 29.3\% and 45.2\%; Morocco, $18.7 \%$ and $21.1 \%$, respectively). Especially in Morocco, this might have affected target BP reduction. In addition, the lower BP targets set for patients with diabetes may have been more difficult to reach during the study duration. Further benefits of treatment, including additional BP lowering and reductions in $\mathrm{CV}$ death and morbidity, may have become evident with a longer follow-up period, and this is a limitation of the study.

These results are comparable to those from the global study, ${ }^{10}$ which showed effective BP lowering with nifedipine in multiple populations, with efficacy related to degree of hypertension, the presence of five or more CV risks, patient age, and whether or not the patient had previously received antihypertensive treatment. The global results also highlighted that the majority of patients were being treated with the lower approved nifedipine dose of $30 \mathrm{mg}$, raising the question as to whether more rigorous control of BP could have been achieved with a $60 \mathrm{mg}$ dose.

Combination treatment with low-dose nifedipine GITS and the angiotensin II receptor blocker (ARB), telmisartan, provides a greater and earlier BP reduction in high risk patients compared with the combination components in monotherapy. ${ }^{16,17}$ Of the patients receiving concomitant medication in this cohort, $29 \%$ in the Middle East and $1 \%$ in Morocco received an ARB with nifedipine, which may suggest that the treatment strategy employed could have been improved.

Physician and patient satisfaction with nifedipine therapy was very high in both cohorts, with a large number of physicians stating that they wished to continue nifedipine treatment. The satisfaction rating was a subjective score, which may have reflected the good tolerability profile of nifedipine more than its efficacy. However, many patients (especially in Morocco) were naïve to hypertension treatment, meaning that there was no frame of reference in which to judge nifedipine therapy.

As discussed above, wider use of the higher approved dose of nifedipine and of potentially better combination therapies might have yielded even greater BP reductions.
This may indicate physician barriers with respect to the safety of higher doses or cost restrictions, or may highlight a potential gap in the awareness of the treating physicians of the latest hypertension research and guidelines. Westernization is increasing in the MEN region; therefore, these countries are relatively new to management of conditions associated with a Western lifestyle, including obesity and hypertension. This might support the call for more practical and simple guidelines which can be widely applicable to individual cases in different clinical settings and countries. ${ }^{16}$

As with most observational trials, a number of limitations were associated with this study: only one North African population was included, compared with seven Middle Eastern countries, and the amalgamation of several Middle Eastern countries may have skewed the population characteristics or hidden trends from individual countries; there may have been a greater effect of patient dropout in the smaller, Moroccan group; limitations of the observational design (including an unknown contributory effect of concomitant medications, unidentified differences attributable to the nifedipine dose prescribed, lack of assessment of optimal treatment regimens in more severe patients, possible underreporting of adverse events [especially if they were expected as part of the known treatment profile, if some physicians did not actively question patients about adverse events, or if differences in perception of safety events existed], and potential effects attributable to different countries or ethnic groups); and the influence of lifestyle differences was not considered.

\section{Conclusion}

Nifedipine is effective and well-tolerated, both as a monotherapy and in combination, for BP reduction in range of patients with $\mathrm{CV}$ risk factors from the Middle East and Morocco. Good rates of BP control were observed in patients with moderate-to-severe hypertension and high added risk, but this may have been improved if prescription rates for the higher dose of nifedipine $(60 \mathrm{mg})$ had been greater. Combination therapy with ARBs may have been especially helpful for high risk patients. Published data in these countries suggest poor prescribing patterns and BP control; these data confirm this trend and suggest that suboptimal dosing may be prevalent.

\section{Acknowledgments}

Editorial support for this manuscript was provided by PAREXEL, and this support was sponsored by Bayer Health Care Pharmaceuticals, Berlin, Germany. 


\section{Disclosure}

The authors report no conflicts of interest in this work.

\section{References}

1. Al Khaja KA, P Sequeira R, Damanhori AH. Evaluation of drug therapy and risk factors in diabetic hypertensives: a study of the quality of care provided in diabetic clinics in Bahrain. J Eval Clin Pract. 2005;11(2): 121-131.

2. Sequeira RP, Jassim KA, Damanhori AH, Mathur VS. Prescribing pattern of antihypertensive drugs by family physicians and general practitioners in the primary care setting in Bahrain. J Eval Clin Pract. 2002;8(4):407-414.

3. Sweileh WM. Treatment of complicated and uncomplicated hypertension with nifedipine in Palestine. Saudi Med J. 2005;26(1):78-83.

4. Harzallah F, Alberti H, Ben Khalifa F. The metabolic syndrome in an Arab population: a first look at the new International Diabetes Federation criteria. Diabet Med. 2006;23(4):441-444.

5. Hossain P, Kawar B, El Nahas M. Obesity and diabetes in the developing world - a growing challenge. $N$ Engl J Med. 2007;356(3):213-215.

6. Gaziano TA, Bitton A, Anand S, Abrahams-Gessel S, Murphy A. Growing epidemic of coronary heart disease in low- and middle-income countries. Curr Probl Cardiol. 2010;35(2):72-115.

7. Law M, Wald N, Morris J. Lowering blood pressure to prevent myocardial infarction and stroke: a new preventive strategy. Health Technol Assess. 2003;7(31):1-94.

8. Mancia G, De Backer G, Dominiczak A, et al; ESH-ESC Task Force on the Management of Arterial Hypertension. 2007 ESH-ESC Practice Guidelines for the Management of Arterial Hypertension: ESH-ESC Task Force on the Management of Arterial Hypertension. J Hypertens. 2007;25(9):1751-1762.

9. Grassi G, Seravalle G, Mancia G. Cardiovascular consequences of poor compliance to antihypertensive therapy. Blood Press. 2011;20(4): 196-203.
10. Ueng KC, Ningling S, El Maksod A, Hung KY, Yuehui Y. Efficacy and tolerability of long-acting nifedipine GITS/OROS monotherapy or combination therapy in hypertensive patients: results of a 12-week international, prospective, multicentre, observational study. Clin Drug Investig. 2011;31(9):631-642.

11. http://www.medicines.org.uk [homepage on the Internet]. Summary of product characteristics for Adalat LA $60 \mathrm{mg}$ prolonged-release tablets. Electronic Medicines Compendium 2010; Available from: http://www. medicines.org.uk/EMC/medicine/20533/SPC/Adalat + LA + $60+\mathrm{mg}$ + prolonged-release + tablets. Accessed February 28, 2011.

12. 1999 World Health Organization-International Society of Hypertension Guidelines for the Management of Hypertension. Guidelines Subcommittee. J Hypertens. 1999;17(2):151-183.

13. European Society of Hypertension-European Society of Cardiology Guidelines Committee. 2003 European Society of HypertensionEuropean Society of Cardiology guidelines for the management of arterial hypertension. J Hypertens. 2003;21(6):1011-1053.

14. Essiarab F, Taki H, El Malki A, Hassar M, Saïle R, Ghalim N. Cardiovascular risk factors prevalence in a Moroccan population. European Journal of Scientific Research. 2011;49(4):581-589.

15. Dixon GT, Johnson ES. Efficacy of antihypertensive drugs. Lancet. 1976;1(7958):515-518.

16. Volpe M, Tocci G. Rethinking targets of blood pressure and guidelines for hypertension clinical management. Nephrol Dial Transplant. 2010;25(11):3465-3471.

17. Mancia G, Parati G, Bilo G, Choi J, Kilama MO, Ruilope LM; TALENT investigators. Blood pressure control by the nifedipine GITS-telmisartan combination in patients at high cardiovascular risk: the TALENT study J Hypertens. 2011;29(3):600-609. Erratum in: J Hypertens. 2011;29(5): 1022.
Integrated Blood Pressure Control

\section{Publish your work in this journal}

Integrated Blood Pressure Control is an international, peer-reviewed open-access journal focusing on the integrated approach to managing hypertension and risk reduction. Treating the patient and comorbidities together with diet and lifestyle modification and optimizing healthcare resources through a multidisciplinary team approach constitute key

\section{Dovepress}

features of the journal. This journal is indexed on American Chemical Society's Chemical Abstracts Service (CAS). The manuscript management system is completely online and includes a very quick and fair peerreview system, which is all easy to use. Visit http://www.dovepress.com/ testimonials.php to read real quotes from published authors. 